\title{
Lack of association of increased antibody levels to mycobacterial hsp65 with rheumatoid arthritis: results from a study of disease discordant twin pairs
}

\author{
J Worthington, A S Rigby, A J MacGregor, A J Silman, D Carthy, W E R Ollier
}

\begin{abstract}
Objectives-To investigate the role of humoral immunity to mycobacterial hsp65 in the aetiology of rheumatoid arthritis.

Methods-Levels of IgG antibodies to recombinant mycobacterial hsp65 were measured by enzyme linked immunosorbent assay (ELISA) in serum samples of 152 twin pairs discordant for RA and in serum samples from 62 normal blood donors.

Results-No significant differences between antibody levels in the subjects with RA compared either with their unaffected twins or with a group of normal blood donors was observed. In the monozygotic twins there was a strong but negative association between levels of antibody to hsp65 and disease status. Zygosity, sex, and HLA status did not significantly affect levels of antibody to hsp65.

Conclusion-Previous reports of an association between hsp65 and RA were not confirmed.
\end{abstract}

(Ann Rheum Dis 1993; 52: 542-544)

Heat shock proteins (hsps) are ubiquitous and highly homologous proteins which may be constitutively expressed or, more often, preferentially expressed, after environmental stress such as infection, heat, or $\mathrm{pH}$ change. Attention has focused on investigating a possible role for mycobacterial hsp65, or equivalent human or bacterial proteins, in rheumatoid arthritis (RA) where immunity to such proteins may be important in the aetiology of the disease.

There have been two previously published studies of response to hsp65 in RA. ${ }^{12}$ Although the two studies found significant increases in levels of antibody to hsp65 in RA, there was considerable overlap between control and patient groups, with many controls having high antibody levels. Further, no relation between antibody level and age, sex, HLA status, or disease activity/severity was observed. More recently, investigation of $\mathrm{T}$ cell responses to hsp65 in patients with RA has not confirmed a role for immunity to this protein, ${ }^{3}$ which had been suggested by earlier studies in the animal model of adjuvant arthritis. ${ }^{4}$
In a further investigation of immunity to hsp65 as a disease specific phenomenon in RA, we measured levels of IgG antibody to Mycobacterium bovis hsp65 in a large group of twins discordant for RA: the unaffected twin provided the perfect age matched control. The possible genetic effect of antibody response to hsp65 was also addressed by comparing the results between monozygotic and dizygotic twins.

\section{Subjects and methods}

SUBJECTS

Twins with at least one member affected by RA were recruited as part of a nationwide study. Preliminary data from this study have been published elsewhere. ${ }^{6}$ The two members of each pair were clinically examined and only those pairs in which one subject satisfied the 1987 American Rheumatism Association criteria were included in this analysis. ${ }^{7}$ Serum samples from $64 \%$ of affected subjects were positive for IgM rheumatoid factor as were 7\% of serum samples from the unaffected twins. All twins were white. Zygosity of twins was confirmed in same sex, HLA identical twins by DNA fingerprinting. ${ }^{8}$ For this analysis 152 disease discordant twin pairs were investigated of whom 64 were monozygotic and 88 dizygotic. There were 23 male-male pairs, 96 female-female pairs, and 33 male-female pairs.

Serum samples from 62 blood donors with a similar age distribution to the twins with RA were obtained from the National Blood Transfusion Service. The age range of the blood donor controls was 50-65 years (median 56 years).

ENZYME LINKED IMMUNOSORBENT ASSAY

This assay used recombinant $M$ bovis hsp65 antigen from the same source as the two previous studies. The only significant changes in protocol were the introduction of a blocking step to reduce non-specific binding by serum samples and the incubation of serum samples with uncoated plates to measure non-specific binding. In a previous study ${ }^{9}$ in which this assay was evaluated the interplate variation was low (coefficient of variation less than $5 \%$ ). The results were calculated by subtracting the nonspecific binding to plates coated with bovine serum albumin (absorbance $280 \mathrm{~nm}$ ) from the binding to plates coated with hsp65 


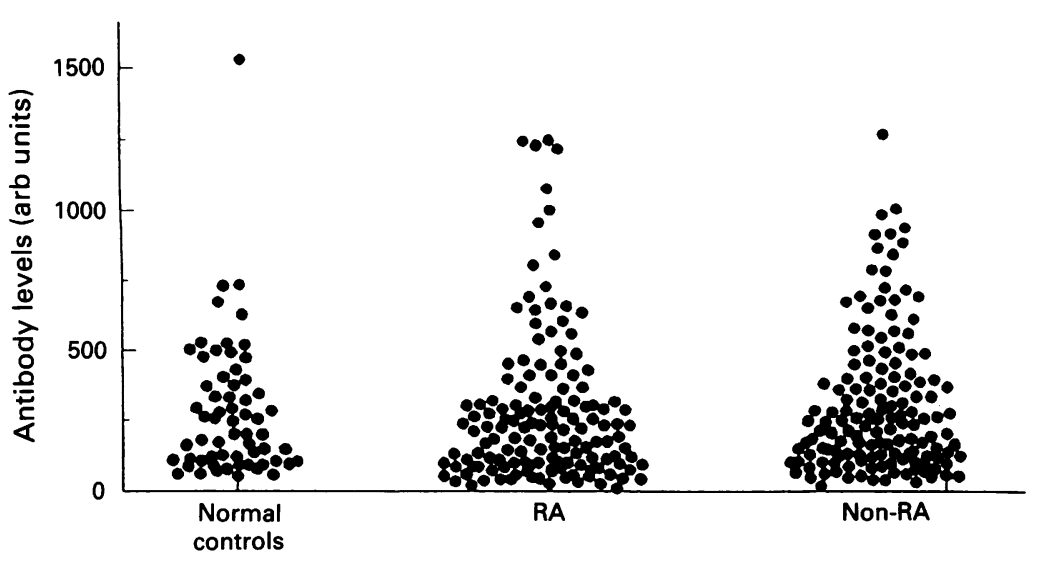

Antibodies to mycobacterial hsp65 in rheumatoid arthritis (RA). Antibodies (IgG) to recombinant mycobacterial hsp 65 in the serum (1/50 dilution) of normal blood donor controls, twins with $R A$, and unaffected twins. Antibody levels were measured by enzyme linked immunosorbent assay (ELISA) and are recorded in arbitrary units of absorbance.

(absorbance $280 \mathrm{~nm}$ ) and are recorded in arbitrary units of absorbance.

STATISTICAL ANALYSIS

The antibody levels in the twins with RA were compared with the unaffected cotwins and with the normal blood donors using the Kruskal-Wallis one way analysis of variance, as the data were not normally distributed.

The hsp exposure within the twin pairs was then compared using a matched case-control approach using conditional logistic regression. ${ }^{10}$ The hsp level was stratified into quartiles. The results are expressed as odds ratios (with $95 \%$ confidence intervals) of the risk of developing RA in each hsp quartile, relative to the lowest quartile.

We also examined the influence of sex, zygosity, and specific HLA-DR alleles in explaining the difference in hsp level between the twin with RA and the unaffected cotwin, using an analysis of variance.

Finally, ignoring disease status, we compared the similarity of hsp levels within the monozygotic and within the dizygotic twin pairs. The genetic influence on hsp65 level was then assessed by calculating the heritability coefficient $\left(h^{2}\right)$ (see Appendix). ${ }^{11}$

\section{Results}

The IgG antibody levels varied considerably in each of the study groups. Levels of IgG antibody to hsp65 in the group of twins with RA were not significantly different from the levels in the unaffected twins nor from levels in a control group with a similar age distribution (Kruskal-Wallis one way ANOVA $\chi_{2}{ }^{2}=3.99 ; p=0 \cdot 14$ ) (figure). Separate analysis of the monozygotic and dizygotic twins suggested that the mean and median antibody levels of the monozygotic unaffected twins was higher than the other groups (table 1).

A strong but negative association $\left(\chi_{\text {trend }}^{2}=11.5 ; \quad \mathrm{p}<0.01\right)$ between increasing quartile of hsp65 antibody and disease status was confirmed in the matched case-control analysis of the monozygotic twin pairs. Subjects in the highest quartile (>370 units)
Table 1 Antibodies to hsp65

\begin{tabular}{llll}
\hline Subject $^{\star}$ & Mean & Median & Range \\
\hline MZ: affected $(\mathrm{n}=64)$ & 266 & 171 & $29-1233$ \\
MZ: unaffected $(\mathrm{n}=64)$ & 339 & 278 & $31-944$ \\
DZ: affected $(\mathrm{n}=88)$ & 274 & 220 & $8-1253$ \\
DZ: unaffected $(\mathrm{n}=88)$ & 290 & 203 & $18-1279$ \\
Blood donors $(\mathrm{n}=62)$ & 277 & 198 & $25-1525$ \\
\hline
\end{tabular}

${ }^{\star} \mathrm{MZ}=$ Monozygotic; $\mathrm{DZ}=$ dizygotic

were nine times more likely than subjects in the lowest quartile ( $<95$ units) to be a non-RA twin. In contrast, there was no association between disease status and antibody level in the dizygotic twins (table 2).

There was no association between antibody levels and any of the HLA-DR antigens. There was, however, a trend towards higher antibody levels in older subjects, but this was not significant (data not shown). Neither the zygosity nor the sex composition of the twin pair had a significant effect on the difference in antibody levels within twin pairs.

The intrapair variance, however, was higher in dizygotic than monozygotic twins, suggesting that hereditary factors may play a part in the control of antibody levels in this twin series. Nonetheless, the estimate of heritability (see Appendix) was only slightly higher in monozygotic $(0 \cdot 296)$ than in dizygotic $(0 \cdot 201)$ twin pairs, suggesting that the contribution of genetic factors to the antibody levels was small. ${ }^{11}$

\section{Discussion}

In common with previous studies, we observed a wide distribution of antibody levels in control and RA groups. Unlike the previous studies, however, we found no significant difference in levels of IgG antibody to mycobacterial hsp65 between affected and unaffected subjects in a group of disease discordant twin pairs. Indeed, in the monozygotic pairs the hsp65 antibody level was higher in the unaffected twin.

The different findings of this study may reflect differences in the hsp65 antigen preparation and in the selection of a control population. The recombinant hsp65 antigen used in the enzyme linked immunosorbent assay (ELISA) was obtained from the same laboratory as that used in the previous studies, but was almost certainly a more recent preparation. Recent studies ${ }^{3}{ }^{12}$ have not shown significant $T$ cell reactivity to hsp65 in RA. Furthermore, in juvenile chronic arthritis reactivity is to Escherichia coli hsp65, a contaminant of the hsp preparation. ${ }^{3}$ Clearly, if $E$ coli hsp 65

Table 2 Association between rheumatoid arthritis and antibodies to hsp65 in discordant twin pairs

\begin{tabular}{|c|c|c|c|}
\hline \multicolumn{2}{|c|}{$M Z$ twins $(n=64)^{\star}$} & \multicolumn{2}{|c|}{$D Z$ twins $(n=88)^{\star}$} \\
\hline sp leve & OR $(95 \% C I)$ & hsp level† & OR $(95 \% C I)$ \\
\hline $\begin{array}{l}29-95 \\
96-165 \\
166-369 \\
370+\end{array}$ & $\begin{array}{l}1.00 \\
0.36(0.10 \text { to } 1 \cdot 26) \\
0.28(0.07 \text { to } 1.06) \\
0.11(0.02 \text { to } 0.48)\end{array}$ & $\begin{array}{l}85-218 \\
219-320 \\
321+\end{array}$ & $\begin{array}{l}1.00 \\
0.45(0.18 \text { to } 1.16) \\
1.39(0.49 \text { to } 3.96) \\
0.60(0.24 \text { to } 1.55)\end{array}$ \\
\hline
\end{tabular}

${ }^{\star} \mathrm{MZ}=$ Monozygotic; $\mathrm{DZ}=$ dizygotic; $\mathrm{OR}=$ odds ratio estimated by conditional logistic regression within the twins. tHSP level in quartiles, determined separately for each group. 
is the relevant antigen, a greater level of contamination in the earlier preparations may explain the increased antibody response in patients with RA detected in the previous studies and not confirmed in this work.

The selection of the control group could also be critical. We observed a non-significant trend towards increased antibody levels with increasing age. In the two previous studies, though the age ranges of the control groups were similar to the RA group, in the study by Tsoulfa $e t a l^{2}$ the mean age of the controls was 20 years younger than the RA group; age distribution information was not available in the paper by Bahr et al. ${ }^{1}$ Clearly, if age influences the antibody levels, then disease discordant twin pairs provide the best age matched data set.

When the twin pairs were analysed as matched cases and controls a strong negative association was observed between antibody levels and disease status in monozygotic twin pairs. This negative association was opposite to that expected from previous studies, but similar to an observation made by Ramos Ruiz et $a l^{13}$ in the rat model of adjuvant arthritis. They found that levels of antibody to hsp65 were lower in immunised rats which developed RA than in those which did not, suggesting a possible protective role for hsp65 specific antibodies. We found no association between HLA-DR status and antibody level, which is in accord with earlier work. ${ }^{2}$ The interaction of rheumatoid factor in the assay was not studied directly; however, the lack of difference between levels of antibody to hsp65 in the affected ( $64 \%$ rheumatoid factor positive) and unaffected ( $7 \%$ positive) subjects indicates a lack of interference of rheumatoid factor in the assay for antibody to hsp65.

The role of antibodies to hsp65 in RA remains unclear. The finding of high levels in so many unaffected subjects together with the lack of disease association observed in this study suggests that immunity to hsp65 is not a disease specific phenomenon, but a normal immunological response to a commonly occurring, highly conserved antigen found in many infectious agents. The simple presence or absence of response to hsp65 may not be important in RA, but the precise nature of reactivity could be. If the pathological event is not recognition of the whole protein but of a specific epitope within that protein, the subsequent loss of tolerance via a mechanism of molecular mimicry may in part explain the aetiology of the disease. This possibility has been investigated with respect to a different heat shock protein. ${ }^{14}$ Antibodies to the $E$ coli DNAJ protein (40 kilodalton) were measured and no difference was found in levels between patients with RA and controls. When reactivity to different epitopes within that protein was investigated using monoclonal antibodies in competitive assays, only the patients with RA had reactivity to one of the epitopes, a nine amino acid sequence which shared $73 \%$ (seven/nine amino acids) homology with a sequence in the third hypervariable region of HLADRB $1^{\star} 0401$. This epitope includes the so called shared epitope sequence, a likely target for aberrant recognition via a mechanism of molecular mimicry in RA.

The immune repertoire may in part be determined by inherited genetic factors, thus the level of antibody or recognition of particular epitopes on antigens might be expected to be more similar in monozygotic twins than in dizygotic twins. In this study we were unable to investigate the recognition of specific epitopes on hsp65, but we did observe a slightly greater variance in antibody levels and a higher estimate of heritability in the monozygotic twins, suggesting only a small genetic component in the determination of antibody levels.

This work was financially supported by the Arthritis and Rheumatism Council. We thank Dr R van der Zee for providing purified, recombinant hsp65. The production and distribution of this protein is financially supported by the UNDP/World Bank/WHO Special Programme for Research and Training in Tropical Diseases. We are grateful to Mr A Farhan for technical assistance and to Mrs I Smith for preparation of the figure.

\section{Appendix: estimates of heritability}

$M Z$ twins $\mathrm{H}^{2}=r$, where

$$
r=\frac{\text { interpair variance }- \text { intrapair variance }}{\text { interpair variance }+ \text { intrapair variance }}
$$

$\mathrm{DZ}$ twins $\mathrm{H}^{2}=2 \mathrm{r}$, where

$$
r=\frac{\text { interpair variance }- \text { intrapair variance }}{\text { interpair variance }+ \text { intrapair variance }}
$$

1 Bahr G M, Rook G A W, Al-Saffar M, van Embden J, Stanford J L, Behbehani K. Antibody levels to mycobacteria in relation to HLA type: evidence for nonHLA-linked high levels of antibody to the $65 \mathrm{kD}$ heat shock protein of $M$ bovis in rheumatoid arthritis. Clin Exp Immunol 1988; 74: 211-5.

2 Tsoulfa G, Rook G A W, van Embden J D A, et al. Raised serum IgG and IgA antibodies to mycobacterial antigens
in rheumatoid arthritis. Ann Rheum Dis 1989; 48: in rheuma

3 Life P, Hassell A, Williams K, et al. Responses to gram negative enteric bacterial antigens by synovial $\mathrm{T}$-cells from JCA patients: recognition of heat shock protein hsp65. F Rheumatol. In press.

4 Cohen I R, Holoshitz J, van Eden W, Frenkel A. T lymphocyte clones illuminate pathogenesis and affect therapy of experimental arthritis. Arthritis Rheum 1985; 28: 841-5.

5 Van Eden W, Thole J E R, van der Zee R, van Embden J D A, Hensen E J, Cohen I R. Cloning of the mycobacterial epitope recognised by $T$ lymphocytes in adjuvant arthritis. Nature 1988; 331: 171-3.

6 Silman A J, MacGregor A, Holligan S, Ollier W E R, Thomson W, Carthy D. Concordance rates of rheumatoid arthritis in twins: results of a nationwide study [abstract]. Arthritis Rheum 1992; 35(suppl): 9 .

7 Arnet F C, Edworthy S M, Liang M H, et al. The American Rheumatism Association 1987 revised criteria for the classification of rheumatoid arthritis. Arthritis Rheum 1988; 31: 315-24.

8 Jeffreys A J, Wilson V, Thein S L. Hypervariable 'minisatellite' regions in human DNA. Nature 1985; 314: 67-73.

9 Brand S R, Worthington J, McIntosh D P, Bernstein R M. Antibody to a 63 kilodalton insect protein in ankylosing Antibody to a 63 kilodalton insect protein in
spondylitis. Ann Rheum Dis 1992; 51: 334-9.

10 SAS Institute Inc. SUGI supplemental library users guide, version 5 edition. Cary, NC: SAS Institute Inc, 1986: 662 version.

11 Emery A E H. Methodology in medical genetics. An introduction to statistical methods. Edinburgh: Churchill Livingstone, 1976

12 Gaston J S H, Life P F, Jenner P J, Tonks S, Colston M $\mathrm{J}$, Bacon $\mathbf{P}$ A. How important are responses to mycobacterial hsp65 in rheumatoid arthritis? $\mathrm{Br} f$ Rheumatol 1991; 30 (suppl 2): 68 .

3 Ramos-Ruiz R, Lopez-Bote J P, Pelayo F, Larraga V, Van der Zee R, Bernabeu C. Cellular and humoral reactivity pattern to the mycobacterial heat shock protein hsp65 in adjuvant arthritis susceptible and resistant Wistar rats. Autoimmunity 1991; 9: 1-5.

14 Albani S, Tuckwell J E, Esparza L, Carson D A, Roudier $J$. The susceptibility sequence to rheumatoid arthritis. Is cross reactive B-cell epitope shared by the Escherichia coli heat shock protein dnaJ and the histocompatibility heat shock protein dna and the histocompatibility 1992; 89: 327-31. 